\title{
Stability of the Stochastic Model for Power Markets with Interval Parameters
}

\author{
Zhanhui Lu, ${ }^{1}$ Mengfan Ji, ${ }^{1}$ Weijuan Wang, ${ }^{1}$ and Gengyin $\mathrm{Li}^{2}$ \\ ${ }^{1}$ School of Mathematics and Physical Science, North China Electric Power University, Beijing 102206, China \\ ${ }^{2}$ State Key Laboratory of Alternate Electrical Power System with Renewable Energy Sources, \\ North China Electric Power University, Beijing 102206, China \\ Correspondence should be addressed to Zhanhui Lu; luzhanhui@ncepu.edu.cn
}

Received 30 May 2016; Accepted 11 October 2016

Academic Editor: Sabri Arik

Copyright (C) 2016 Zhanhui Lu et al. This is an open access article distributed under the Creative Commons Attribution License, which permits unrestricted use, distribution, and reproduction in any medium, provided the original work is properly cited.

\begin{abstract}
Pertaining to the random nature of demand sides and the range of demand elasticity with suppliers and consumers, a stochastic model for power markets with interval parameters is described to illustrate uncertain external disturbances, which is a generalization of the Alvarado dynamic model, stochastic model, and interval model. The interval stochastic stability criteria of the provided model are investigated by the theory of economics, interval dynamical system, and the theory stability of stochastic differential equations. The conclusions indicate that the demand elasticity stable interval can be calculated and the random excitation intensity does not impact the system stability. Some numerical examples are given to show the applicability and validity of the obtained results from a statistical perspective.
\end{abstract}

\section{Introduction}

In March 2015, Several Opinions on Further Deepening the Reform of Power System, issued by the Central Committee of the Communist Party of China and the State Council, pointed out the need to further improve the level of guaranteeing supply and demand balance mainly on demand side management. Government departments must maintain the overall balance of power supply, in the direction of marketization, from the two aspects of the demand side and supply side. Effective competition on both power generation and demand side, as well as independent market subjects, is needed, focusing on building a diversified-subjects, orderly competition electricity trading pattern, in order to form an electricity price mechanism adapting to the market and stimulate the vitality of the enterprise, finally making market a decisive role in the allocation of resources.

The power market is the generic terms of the exchange relationships between the supply and demand sides, based on fairness, competition, voluntary, and mutual benefits. Power market stability is essential to ensure that the supply of electricity is economically reliable, so the research on it makes theoretical and practical significance on regulating the market supply and demand, setting up market rules, and supervising market operation $[1,2]$. Study on power market stability uses knowledge involving mathematics, economics, and power system, applying mathematical modeling method, to analyze models dynamically and determine the economy stability. In recent years, a variety of competitive game models are widely applied in power market balancing research [36], mainly including Cournot model [3], Stackelberg model [4], and the supply function model [5]. In 1990, Beavis and Dobbs began to study economic system stability [7]. And the power market stability was first proposed by Alvarado using differential algebraic equations and eigenvalue method, combining market dynamics, setting up continuous power market dynamics models $[8,9]$. Based on models above, a series of conditions to determine the power market and practical stability are provided in $[10,11]$. Considering the instantaneously clearing of power market, the cyclic pattern of load demand and discrete biding strategy, the power market is described as a periodic difference system in [12]. In [13], according to the different demand utility, supply functions, and price forecasting models, a series of power market discrete difference models depicting autonomy, heteronomy continuous, or discrete linear periodical systems 
are provided, and the Lyapunov stability of these models is systematically analyzed. In fact, discussions about stability mentioned above are about Lyapunov asymptotical stability of equilibrium in the deterministic differential equation theory.

Stochastic factors have been taken into consideration in the research of models for financial market. References $[14,15]$ study some generalizations of the Heston model with stochastic volatility in stock market, analyzing the statistical properties of the escape times and the effect role on the system. In [16], several models describing the stock market and their statistical properties are studied and compared. In $[17,18]$, hitting time and escape time distributions of stock price returns are analyzed, and then the distributions obtained from different models are compared with those obtained from real market data. These papers about financial market researching nonlinear model focus more on the numerical stimulation to compare different models.

At present, some scholars have attributed specific systems to stochastic or interval dynamical systems in order to discuss system stability $[19,20]$. In power system, due to effects from measurement error, model simplifying, and external interference, some system parameters cannot be measured accurately. An electricity model under Gauss type random excitation has been structured in [20], theoretically proving the power system mean stable and mean-square stable under small Gauss type random excitation. In [21], p-moment stability of power system under small Gauss type random excitation is verified when $p$ is greater than or equal to 2 using Lyapunov method, Ito isometry formula and matrix theory. In [22, 23], p-moment stability of power system is also discussed. In the power market, considering that demand elasticity is uncertain and ranging within interval, a power market interval model is described, and the conditions to determine the interval stability are provided in [24]. In [25], a class of power market stochastic dynamic model is presented, and the conditions to determine the mean stability are provided considering the randomness of the electricity demanding. Factors including economy increasing, industrial structure, and energy consumption structure, such as the uncertainty of wind power fluctuation and interval, jointly become a factor that makes demand elasticity of both sides and the power demand uncertain and influence the stability of power market. Uncertainty includes randomness and fuzziness, whose generating mechanism and physical meanings both differ from each other [26]. As a result, it is necessary to integrate the randomness of electricity demand with interval features of consumer demand elasticity changing in the research on power market stability.

In this paper, random factors are taken into consideration on a basis of power market interval models, presenting a stochastic model for power markets with interval parameters, combining the thought of randomness and interval. The stochastic differential equation theory is nowadays applied in many fields like finance, systematic science, and engineering control [27-29]. Adopting theories including economy, interval dynamical system, and stochastic differential equation to analyze the model's stability, theorems of interval stochastic stability are provided and proved as well. It turned out that using the theory's stability criterion is able to determine the range of suppliers and consumers demand elasticity which makes system stable. Finally, the validity of results is verified by using exact power market examples and stimulation analysis in Matlab. The results generate conclusions about power market certainty models [8], interval models [24], and stochastic models [25].

In this text, $|\cdot|$ means the Euclidean norm of a vector, $\lambda_{\text {max }}(\cdot)$ and $\lambda_{\min }(\cdot)$, respectively, denote the matrix's maximum and minimum eigenvalue. $I$ is unit matrix.

\section{The Stochastic Model for Power Markets with Interval Parameters}

Let the generator cost functions and consumer utility functions be quadratic with $m$-suppliers and $n$-consumers. When a supplier observes a power market price $\lambda$ higher than its production cost $\lambda_{g i}$, the supplier will expand production until the marginal cost of production equals the price. The rate of expansion is proportional to the difference between the observed market price and the actual cost of production. Let the generation power output be $P_{g i}$ from supplier $i$, and the speed it can respond with is supplier-dependent, denoted by a time constant $\tau_{g i}$ for supplier $i$. The following model is proposed by Alvarado to describe power market dynamic behavior under the hypothesis in [8]:

$$
\tau_{g i} \dot{P}_{g i}=\lambda-b_{g i}-c_{g i} P_{g i} \quad(i=1,2, \ldots, m),
$$

where $P_{g i}$ is the generation power output, $\tau_{g i}$ is the responding speed of power output, $\lambda$ is the price at any given time, $b_{g i}+c_{g i} P_{g i}$ is the marginal cost of supplier $i, c_{g i}$ is the demand elasticity of supplier $i$, and $b_{g i}$ is the linear cost coefficient of supplier $i$.

And for the consumers, the model is formed like

$$
\tau_{d j} \dot{P}_{d j}=-\lambda+b_{d j}+c_{d j} P_{d j} \quad(j=1,2, \ldots, n),
$$

where $P_{d j}$ is a consumer's power demand, $\tau_{d j}$ is the speed of consumption demand expansion, $b_{d j}+c_{d j} P_{d j}$ is the marginal benefit of consumer $j, c_{d j}$ is the demand elasticity of consumer $j$, and $b_{d j}$ is the linear cost coefficient of consumer $j$. In addition, the equation holds:

$$
\sum_{i=1}^{m} P_{g i}=\sum_{j=1}^{n} P_{d j}
$$

Considering the congestion of power market, using flow distribution factors, a single congested condition can be represented:

$$
\begin{aligned}
& s_{g 1} P_{g 1}+s_{g 2} P_{g 2}+\cdots+s_{g m} P_{g m}+s_{d 1} P_{d 1}+s_{d 2} P_{d 2}+\cdots \\
& +s_{d n} P_{d n}=h_{1}
\end{aligned}
$$

Usually, a complete model with $n_{S}$-congested condition, $m$-suppliers, and $n$-consumers is described as follows:

$$
\left[\begin{array}{ll}
T & 0 \\
0 & 0
\end{array}\right]\left[\begin{array}{c}
\dot{\widetilde{P}} \\
\dot{\widetilde{\Lambda}}
\end{array}\right]=\left[\begin{array}{cc}
C & S^{\mathrm{T}} \\
S & 0
\end{array}\right]\left[\begin{array}{c}
\widetilde{P} \\
\widetilde{\Lambda}
\end{array}\right]+\left[\begin{array}{l}
0 \\
h
\end{array}\right],
$$


where $T=\operatorname{diag}\left\{\tau_{g 1}, \tau_{g 2}, \ldots, \tau_{g m}, \tau_{d 1}, \tau_{d 2}, \ldots, \tau_{d n}\right\}, \tau_{g i}>0$, $\tau_{d j}>0, C=\operatorname{diag}\left\{-c_{g 1},-c_{g 2}, \ldots,-c_{g m}, c_{d 1}, c_{d 2}, \ldots, c_{d n}\right\}$, $\widetilde{\Lambda}=\left[\begin{array}{llll}\lambda & \mu_{1} & \cdots & \mu_{n_{S}}\end{array}\right], i=1,2, \ldots, m, j=1,2, \ldots, n, \widetilde{\Lambda} \in$ $R^{n_{s}+1}, \widetilde{P} \in R^{m+n}, \mu_{k}\left(k=1,2, \ldots, n_{s}\right)$ denotes congested Lagrange multiplier, and matrix $S$ stands for sensitivities of the constraints

$$
\left[\begin{array}{cccccc}
1 & \cdots & 1 & -1 & \cdots & -1 \\
s_{g 11} & \cdots & s_{g 1 m} & s_{d 11} & \cdots & s_{d 1 n} \\
\vdots & & \vdots & \vdots & & \vdots \\
s_{g n_{S} 1} & \cdots & s_{g n_{S} m} & s_{d n_{S} 1} & \cdots & s_{d n_{s} n}
\end{array}\right]
$$

the first line of the matrix denotes the power balance conditions; $b=\left[\begin{array}{lllllllll}-b_{g 1} & -b_{g 2} & \cdots & -b_{g m} & \cdots & b_{d 1} & b_{d 2} & \cdots & b_{d n}\end{array}\right]^{\mathrm{T}}$ is a cost vector of linear coefficients; $h=\left[\begin{array}{lllll}0 & h_{1} & h_{2} & \cdots & h_{n_{S}}\end{array}\right]^{\mathrm{T}}$ is a constant vector; and $h_{i}$ is the value of the right-hand side in the constraint equations in the remaining positions for $i=1,2, \ldots, n_{S}$.

Since the system in equation (5) has at least one equilibrium point, the initial system can be turned into

$$
\left[\begin{array}{ll}
T & 0 \\
0 & 0
\end{array}\right]\left[\begin{array}{l}
\dot{P} \\
\dot{\Lambda}
\end{array}\right]=\left[\begin{array}{cc}
C & S^{\mathrm{T}} \\
S & 0
\end{array}\right]\left[\begin{array}{l}
P \\
\Lambda
\end{array}\right] .
$$

The demand elasticity of both suppliers and consumers varies in some ranges, as the former is influenced by installed capacity and $s$ growing speed of generating energy, and the latter is affected by growing speed of power consumption. Let the range be $\underline{c}_{g i} \leq c_{g i} \leq \bar{c}_{g i}$ and $\underline{c}_{d j} \leq c_{d j} \leq \bar{c}_{d j}, i=1,2, \ldots, m$, $j=1,2, \ldots, n$.

Then,

$$
\begin{aligned}
& \underline{C}=\operatorname{diag}\left\{-\bar{c}_{g 1},-\bar{c}_{g 2}, \ldots,-\bar{c}_{g m},-_{d 1}, \underline{c}_{d 2}, \ldots, \underline{c}_{d n}\right\}, \\
& \bar{C}=\operatorname{diag}\left\{-\underline{c}_{g 1},-\underline{c}_{g 2}, \ldots,-\underline{c}_{g m}, \bar{c}_{d 1}, \bar{c}_{d 2}, \ldots, \bar{c}_{d n}\right\} .
\end{aligned}
$$

If $C=(\bar{C}+\underline{C}) / 2, \widetilde{C}=(\bar{C}-\underline{C}) / 2, C_{I}=C+\Delta C$, then $\Delta C \in[-\widetilde{C}, \widetilde{C}]$. Equation (7) can be described as the interval dynamic system model below:

$$
\left[\begin{array}{ll}
T & 0 \\
0 & 0
\end{array}\right]\left[\begin{array}{c}
\dot{P} \\
\dot{\Lambda}
\end{array}\right]=\left[\begin{array}{cc}
C_{I} & S^{\mathrm{T}} \\
S & 0
\end{array}\right]\left[\begin{array}{l}
P \\
\Lambda
\end{array}\right],
$$

where $C_{I}=[\underline{C}, \bar{C}]$ is an interval matrix, $C \in C_{I}$.

Usually, there exists $m+n>n_{S}+1$. Let $r(S)=n_{S}+1$ and $S=\left(S_{1}, S_{2}\right)$, where $S_{1}$ is a nonsingular $\left(n_{S}+1\right) \times\left(n_{S}+1\right)$-order submatrix of $S$. Dividing $T$ and $C_{I}$ into

$$
\begin{aligned}
T & =\left[\begin{array}{cc}
T_{1} & 0 \\
0 & T_{2}
\end{array}\right], \\
C_{I} & =\left[\begin{array}{cc}
C_{1 I} & 0 \\
0 & C_{2 I}
\end{array}\right],
\end{aligned}
$$

where $T_{1}$ and $C_{1 I}$ are $\left(n_{S}+1\right) \times\left(n_{S}+1\right)$-order diagonal matrices, $T_{2}$ and $C_{2 I}$ are $q \times q$-order diagonal matrices, and $q=(m+n)-\left(n_{s}+1\right)$. Similarly, matrices $C_{1 I}$ and $C_{2 I}$ are interval matrices with the form like $\left[C_{1}, \overline{C_{1}}\right]$ and $\left[\underline{C_{2}}, \overline{C_{2}}\right]$, where $C_{1} \in C_{1 I}, C_{2} \in C_{2 I}$.

The power market interval model can be derived after variations:

$$
T_{3} d P_{2}(t)=\left(C_{2 I}+S_{3}^{\mathrm{T}} C_{1 I} S_{3}\right) P_{2}(t) d t
$$

Besides the interval features of demand elasticity for suppliers and consumers, considering the stochasticity of electricity demand, a random excitation is added to the right side of equation (11) and then the model with interval parameters is written as follows:

$$
T_{3} d P_{2}(t)=\left(C_{2 I}+S_{3}^{\mathrm{T}} C_{1 I} S_{3}\right) P_{2}(t) d t+Q d B(t),
$$

where $t \in\left[t_{0},+\infty\right)$, the initial value $P_{2}\left(t_{0}\right)=P_{0}$ is bounded, and $B(t)$ is Wiener process and independent of $P_{2}(t)$, which is consumers electricity demand changed with $t . Q$ is the strength of random excitation representing the maximum value possible. The random excitation can be deemed as power demand stochastic fluctuation caused by objective factors, and these fluctuation are presumed to be Gaussian Wiener process generally.

Remark 1. Let $Q=0, C_{1 I}=C_{1}, C_{2 I}=C_{2} ; Q=0$; $C_{1 I}=C_{1}, C_{2 I}=C_{2}$ in model (12), it can be simplified to the deterministic dynamic model proposed by Alvarado in [8], the interval dynamic system model in [24] and the stochastic dynamic model for power market in [25], respectively. Therefore, the model for power market (12) considering both the randomness of power demand and interval features of demand elasticity for suppliers and consumers, is a generalization of deterministic model, interval model and stochastic model proposed by Alvarado, instead of only considering one of the interval or stochastic features.

\section{The Mean Interval Stability}

In this part, we consider the stability of power market uncertain stochastic model (12). The definition of interval matrices in differential equation interval dynamical system is as follows.

For any $1 \leq i \leq m$ and $1 \leq j \leq n, m \times n$ matrices $\underline{A}=$ $\left(u_{i j}\right)_{m \times n}$, and $\underline{A}=\left(u_{i j}\right)_{m \times n}$ satisfy $u_{i j} \leq v_{i j}$. Let $m \times n$ matrix be

$$
\begin{aligned}
& {[\underline{A}, \bar{A}]=\left\{A=\left(a_{i j}\right)_{m \times n}: u_{i j} \leq a_{i j} \leq v_{i j}, 1 \leq i \leq m, 1\right.} \\
& \quad \leq j \leq n\} .
\end{aligned}
$$

Consider this interval dynamic system

$$
d X(t)=A_{I} X(t) d t .
$$

Definition 2 (see [30]). For any $A_{I} \in[\bar{A}, \underline{A}]$, if the zero solution of system (14) is asymptotically stable, then system (14) is interval stable.

With Definition 2, referring to the definition of mean stability in [31], the definition of system mean interval stability is provided. 
Definition 3. For any $A_{I} \in[\bar{A}, \underline{A}]$, if the solution process of the stochastic model for power markets with interval parameters (12) is asymptotically stable and it satisfies $\lim _{t \rightarrow \infty} E|X(t)|<c$, where $c$ is a constant value greater than zero, then system (14) is interval stable.

The differential operator $L$ is [19]

$$
L=\frac{\partial}{\partial t}+\sum_{i=1}^{n} f_{i}(X, t) \frac{\partial}{\partial x_{i}},
$$

where $f(X, t)=A_{I} X(t)$.

Next, we give some preliminary lemmas, which play an important role in the proof of the stability theorem.

Lemma 4 (see [32]). If $A$ is a $n \times n$ real symmetric positive definite matrix and $x$ is a n-dimensional column vector, then $\lambda_{\text {min }}(A) X^{T} X \leq X^{T} A X \leq \lambda_{\max }(A) X^{T} X$.

Lemma 5 (see [33]). For $\forall X_{0}$ and $t \geq t_{0}$, there must exist

$$
E\left|X\left(t ; t_{0}, X_{0}\right)\right|^{p} \leq \frac{c_{2}}{c_{1}}\left|X_{0}\right|^{p} e^{-c_{3}\left(t-t_{0}\right)},
$$

if the conditions below are satisfied:

(i) Linear ordinary differential equation $d X(t)=A X(t) d t$ has equilibrium solutions.

(ii) There exists a positive definite function $V(X, t)$ and positive constants $c_{1}, c_{2}, c_{3}$, satisfying $L V(X, t) \leq$ $-c_{3} V(X, t)$ and $c_{1}|X|^{p} \leq V(X, t) \leq c_{2}|X|^{p}$ when $(X, t) \in R^{n} \times\left[t_{0}, \infty\right)$.

The inequality means that the equilibrium solutions of the system are p-moment exponential stable.

Lemma 6 (see [32]). If $A$ is a $n \times n$ real symmetric positive definite matrix, then there must exist an invertible symmetric matrix $B$ satisfying $A=B^{2}$.

Lemma 7 (see [32]). If there is a $n \times n$ real symmetric positive definite matrix $Z$, which makes the stochastic model for power markets with interval parameters (12) satisfying these two conditions

$$
\begin{aligned}
& h_{1}\left|T_{33}^{-1} P_{2}\right|^{2} \leq\left(T_{33}^{-1} P_{2}\right)^{T} Z T_{33}^{-1} P_{2} \leq h_{2}\left|T_{33}^{-1} P_{2}\right|^{2} ; \\
& \lambda_{\max }\left(Z^{1 / 2} T_{33}^{T} C_{3} T_{33} Z^{-1 / 2}+Z^{-1 / 2} T_{33}^{T} C_{3} T_{33} Z^{1 / 2}\right) \\
& \quad+2\left(\left\|\widetilde{C}_{2}\right\|+\left\|\widetilde{C}_{1}\right\| \cdot\left\|S_{3}\right\|^{2}\right) \cdot\left\|T_{33}\right\|^{2} \cdot \sqrt{\frac{\|Z\|}{h_{1}}}<0,
\end{aligned}
$$

then there exists $E\left|e^{T_{33}^{T}\left(C_{2 I}+S_{3}^{T} C_{1 I} S_{3}\right) T_{33}\left(t-t_{0}\right)} X_{0}\right|^{2} \leq$ $\beta\left|X_{0}\right|^{2} e^{-\alpha\left(t-t_{0}\right)}$, where $\alpha$ is a positive constant, $\beta=h_{2} / h_{1}$.

Proof. Since $T_{3}$ is reversible, there must be a reversible matrix $T_{33}$, satisfying $T_{3}=\left(T_{33}^{-1}\right)^{\mathrm{T}} T_{33}^{-1}$. By substituting it into (12), we have

$$
\begin{aligned}
\left(T_{33}^{-1}\right)^{\mathrm{T}} T_{33}^{-1} d P_{2}(t)= & \left(C_{2 I}+S_{3}^{\mathrm{T}} C_{1 I} S_{3}\right) P_{2}(t) d t \\
& +Q d B(t) .
\end{aligned}
$$

Both sides of the equation premultiply $T_{33}^{\mathrm{T}}$ and let $X(t)=$ $T_{33}^{-1} P_{2}(t)$; then, $d X(t)=T_{33}^{-1} d P_{2}(t)$ and (12) can be written as

$$
\begin{aligned}
d X(t)= & T_{33}^{\mathrm{T}}\left(C_{2 I}+S_{3}^{\mathrm{T}} C_{1 I} S_{3}\right) T_{33} X(t) d t \\
& +T_{33}^{\mathrm{T}} Q d B(t) .
\end{aligned}
$$

The explicit expression of its solution [34] is

$$
\begin{aligned}
X(t)= & e^{T_{33}^{\mathrm{T}}\left(C_{2 I}+S_{3}^{\mathrm{T}} C_{1 I} S_{3}\right) T_{33}\left(t-t_{0}\right)} X_{0} \\
& +\int_{t_{0}}^{t} e^{T_{33}^{\mathrm{T}}\left(C_{2 I}+S_{3}^{\mathrm{T}} C_{1 I} S_{3}\right) T_{33}(t-s)} T_{33}^{\mathrm{T}} \mathrm{Q} d B(\mathrm{~s}) .
\end{aligned}
$$

Let $Q=0$; system (12) can be simplified as an interval model like this

$$
T_{3} d P_{2}(t)=\left(C_{2 I}+S_{3}^{\mathrm{T}} C_{1 I} S_{3}\right) P_{2}(t) d t
$$

and the explicit expression of its solution is

$$
X(t)=e^{T_{33}^{\mathrm{T}}\left(C_{2 I}+S_{3}^{\mathrm{T}} C_{1 I} S_{3}\right) T_{33}\left(t-t_{0}\right)} X_{0} .
$$

Structure a Lyapunov function $V(X, t)=X^{\mathrm{T}} Z X$. Since $h_{1}\left|T_{33}^{-1} P_{2}\right|^{2} \leq\left(T_{33}^{-1} P_{2}\right)^{\mathrm{T}} Z T_{33}^{-1} P_{2} \leq h_{2}\left|T_{33}^{-1} P_{2}\right|^{2}$, we have $h_{1}|X|^{2} \leq X^{\mathrm{T}} Z X \leq h_{2}|X|^{2}$. It is obvious that $V(X, t)$ has an infinitesimal upper bound and infinite lower bound.

Let $C_{3}=C_{2}+S_{3}^{\mathrm{T}} C_{1} S_{3}$. Since $\partial\left(X^{\mathrm{T}} Z X\right) / \partial t=0$, we obtain

$$
\begin{aligned}
L V= & \sum_{i=1}^{k} f_{i}(X, t) \frac{\partial}{\partial x_{i}}\left(X^{\mathrm{T}} Z X\right)=2 X^{\mathrm{T}} Z f(X, t) \\
= & 2 X^{\mathrm{T}} Z T_{33}^{\mathrm{T}} C_{3} T_{33} X \\
& +2 X^{\mathrm{T}} Z T_{33}^{\mathrm{T}}\left(\Delta C_{2}+S_{3}^{\mathrm{T}} \Delta C_{1} S_{3}\right) T_{33} X .
\end{aligned}
$$

By Lemma 4, the first item of the right-hand side can be turned into

$$
\begin{aligned}
2 & X^{\mathrm{T}} Z T_{33}^{\mathrm{T}} C_{3} T_{33} X=X^{\mathrm{T}}\left[Z ^ { 1 / 2 } \left(Z^{1 / 2} T_{33}^{\mathrm{T}} C_{3} T_{33} Z^{-1 / 2}\right.\right. \\
& \left.\left.+Z^{-1 / 2} T_{33}^{\mathrm{T}} C_{3} T_{33} Z^{1 / 2}\right) Z^{1 / 2}\right] X=\left(Z^{1 / 2} X\right)^{\mathrm{T}} \\
& \cdot\left(Z^{1 / 2} T_{33}^{\mathrm{T}} C_{3} T_{33} Z^{-1 / 2}+Z^{-1 / 2} T_{33}^{\mathrm{T}} C_{3} T_{33} Z^{1 / 2}\right) \\
& \cdot Z^{1 / 2} X \leq \lambda_{\max }\left(Z^{1 / 2} T_{33}^{\mathrm{T}} C_{3} T_{33} Z^{-1 / 2}\right. \\
& \left.+Z^{-1 / 2} T_{33}^{\mathrm{T}} C_{3} T_{33} Z^{1 / 2}\right) X^{\mathrm{T}} Z X
\end{aligned}
$$


For any $\varepsilon>0$, there is $2 a b \leq \varepsilon a^{2}+b^{2} / \varepsilon$. Hence, the second item of the right-hand side of equation (23) can be formed as

$$
\begin{aligned}
2 X^{\mathrm{T}} Z T_{33}^{\mathrm{T}}\left(\Delta C_{2}+S_{3}^{\mathrm{T}} \Delta C_{1} S_{3}\right) T_{33} X \\
\leq 2\left|X^{\mathrm{T}} Z^{1 / 2}\right|\left|Z^{1 / 2} T_{33}^{\mathrm{T}}\left(\Delta C_{2}+S_{3}^{\mathrm{T}} \Delta C_{1} S_{3}\right) T_{33} X\right| \\
\leq \varepsilon\left|X^{\mathrm{T}} Z^{1 / 2}\right|^{2} \\
\quad+\frac{1}{\varepsilon}\left|Z^{1 / 2} T_{33}^{\mathrm{T}}\left(\Delta C_{2}+S_{3}^{\mathrm{T}} \Delta C_{1} S_{3}\right) T_{33} X\right|^{2} \\
\leq \varepsilon X^{\mathrm{T}} Z X+\frac{1}{\varepsilon}\|Z\| \cdot\left\|T_{33}\right\|^{4} \cdot\left\|\left(\Delta C_{2}+S_{3}^{\mathrm{T}} \Delta C_{1} S_{3}\right)\right\|^{2} \\
\quad \cdot|X|^{2} .
\end{aligned}
$$

By the norm property, we have

$$
\begin{aligned}
\left\|\Delta C_{2}+S_{3}^{\mathrm{T}} \Delta C_{1} S_{3}\right\| & \leq\left\|\Delta C_{2}\right\|+\left\|\Delta C_{1}\right\| \cdot\left\|S_{3}\right\|^{2} \\
& \leq\left\|\widetilde{C}_{2}\right\|+\left\|\widetilde{C}_{1}\right\| \cdot\left\|S_{3}\right\|^{2} .
\end{aligned}
$$

By the condition of $h_{1}|X|^{2} \leq X^{\mathrm{T}} Z X$ we can obtain $|X|^{2} \leq$ $X^{\mathrm{T}} Z X / h_{1}$, and

$$
\begin{aligned}
& 2 X^{\mathrm{T}} Z T_{33}^{\mathrm{T}}\left(\Delta C_{2}+S_{3}^{\mathrm{T}} \Delta C_{1} S_{3}\right) T_{33} X \\
& \quad \leq\left(\varepsilon+\frac{\|Z\| \cdot\left\|T_{33}\right\|^{4} \cdot\left(\left\|\widetilde{C}_{2}\right\|+\left\|\widetilde{C}_{1}\right\| \cdot\left\|S_{3}\right\|^{2}\right)^{2}}{\varepsilon \cdot h_{1}}\right) \\
& \quad \cdot X^{\mathrm{T}} Z X .
\end{aligned}
$$

Let $\varepsilon=\left\|T_{33}\right\|^{2} \cdot\left(\left\|\widetilde{C}_{2}\right\|+\left\|\widetilde{C}_{1}\right\| \cdot\left\|S_{3}\right\|^{2}\right) \cdot \sqrt{\|Z\| / h_{1}}$; then, we acquire

$$
\begin{aligned}
& 2 X^{\mathrm{T}} Z T_{33}^{\mathrm{T}}\left(\Delta C_{2}+S_{3}^{\mathrm{T}} \Delta C_{1} S_{3}\right) T_{33} X \\
& \leq 2\left\|T_{33}\right\|^{2} \cdot\left(\left\|\widetilde{C}_{2}\right\|+\left\|\widetilde{C}_{1}\right\| \cdot\left\|S_{3}\right\|^{2}\right) \cdot \sqrt{\frac{\|Z\|}{h_{1}}} \\
& \cdot X^{\mathrm{T}} Z X .
\end{aligned}
$$

Substituting (24) and (28) into (23), we have

$$
\begin{aligned}
L V & \leq\left[\lambda _ { \operatorname { m a x } } \left(Z^{1 / 2} T_{33}^{\mathrm{T}} C_{3} T_{33} Z^{-1 / 2}\right.\right. \\
& \left.+Z^{-1 / 2} T_{33}^{\mathrm{T}} C_{3} T_{33} Z^{1 / 2}\right)+2\left\|T_{33}\right\|^{2} \cdot\left(\left\|\widetilde{C}_{2}\right\|+\left\|\widetilde{C}_{1}\right\|\right. \\
& \left.\left.\cdot\left\|S_{3}\right\|^{2}\right) \cdot \sqrt{\frac{\|Z\|}{h_{1}}}\right] X^{\mathrm{T}} Z X .
\end{aligned}
$$

Owing to $V(X, t)=X^{\mathrm{T}} Z X$ and other conditions, there must exist $h_{3}>0$ such that $L V(X, t) \leq-h_{3} V(X, t)$. Since $h_{1}|X|^{2} \leq X^{\mathrm{T}} Z X \leq h_{2}|X|^{2}$, we confirm the system satisfies conditions in Lemma 5 , so for any $A_{I} \in[\bar{A}, \underline{A}]$,
$E\left|X\left(t ; t_{0}, X_{0}\right)\right|^{2} \leq h_{2}\left|X_{0}\right|^{2} e^{-h_{3}\left(t-t_{0}\right)} / h_{1}$. Let $h_{2} / h_{1}=\beta$ and $h_{3}=\alpha$; then, $\alpha>0$ and $\beta>0$. Owing to equation (22), we have

$$
E\left|e^{T_{33}^{\mathrm{T}}\left(C_{2 I}+S_{3}^{\mathrm{T}} C_{1 I} S_{3}\right) T_{33}\left(t-t_{0}\right)} X_{0}\right|^{2} \leq \beta\left|X_{0}\right|^{2} e^{-\alpha\left(t-t_{0}\right)} .
$$

Considering any given initial time $s \in\left[t_{0}, t\right)$, let the initial time of these varieties of stationary curve be $X(s)=T_{33}^{\mathrm{T}} \mathrm{Q}$; according to Lemma 5, we know that any solution curve satisfies

$$
\begin{aligned}
E\left|X\left(t ; s, T_{33}^{\mathrm{T}} \mathrm{Q}\right)\right|^{2} & =E\left|e^{T_{33}^{\mathrm{T}}\left(C_{21}+S_{3}^{\mathrm{T}} C_{1 I} S_{3}\right) T_{33}(t-s)} T_{33}^{\mathrm{T}} \mathrm{Q}\right|^{2} \\
& \leq \beta\left|T_{33}^{\mathrm{T}} \mathrm{Q}\right|^{2} e^{-\alpha(t-s)} .
\end{aligned}
$$

Theorem 8. If there exists a positive definite matrix $Z$, which makes

$$
\begin{aligned}
& h_{1}\left|T_{33}^{-1} P_{2}\right|^{2} \leq\left(T_{33}^{-1} P_{2}\right)^{T} Z T_{33}^{-1} P_{2} \leq h_{2}\left|T_{33}^{-1} P_{2}\right|^{2}, \\
& \lambda_{\text {max }}\left(Z^{1 / 2} T_{33}^{T} C_{3} T_{33} Z^{-1 / 2}+Z^{-1 / 2} T_{33}^{T} C_{3} T_{33} Z^{1 / 2}\right) \\
& \quad+2\left(\left\|\widetilde{C}_{2}\right\|+\left\|\widetilde{C}_{1}\right\| \cdot\left\|S_{3}\right\|^{2}\right) \cdot\left\|T_{33}\right\|^{2} \cdot \sqrt{\frac{\|Z\|}{h_{1}}}<0,
\end{aligned}
$$

where $h_{1}$ and $h_{2}$ are both positive constant, then model (12) is mean interval stable.

Proof. According to Cauchy-Schwarz inequality, we have

$$
\begin{aligned}
& (E|X(t)|)^{2} \leq E|X(t)|^{2}=E\left[X^{\mathrm{T}}(t) X(t)\right] \\
& =E\left[\left(e^{T_{33}^{\mathrm{T}}\left(C_{2 I}+S_{3}^{\mathrm{T}} C_{1 I} S_{3}\right) T_{33}\left(t-t_{0}\right)} X_{0}\right)^{\mathrm{T}}\right. \\
& \left.\cdot e^{T_{33}^{\mathrm{T}}\left(C_{2 I}+S_{3}^{\mathrm{T}} C_{1 I} S_{3}\right) T_{33}\left(t-t_{0}\right)} X_{0}\right] \\
& +E\left[\left(e^{T_{33}^{\mathrm{T}}\left(C_{2 I}+S_{3}^{\mathrm{T}} C_{1 I} S_{3}\right) T_{33}\left(t-t_{0}\right)} X_{0}\right)^{\mathrm{T}}\right. \\
& \left.\cdot \int_{t_{0}}^{t} e^{T_{33}^{\mathrm{T}}\left(C_{2 I}+S_{3}^{\mathrm{T}} C_{1 I} S_{3}\right) T_{33}(t-s)} T_{33}^{\mathrm{T}} Q d B(s)\right] \\
& +E\left[\left(\int_{t_{0}}^{t} e^{T_{33}^{\mathrm{T}}\left(C_{2 I}+S_{3}^{\mathrm{T}} C_{1 I} S_{3}\right) T_{33}(t-s)} T_{33}^{\mathrm{T}} Q d B(s)\right)^{\mathrm{T}}\right. \\
& \left.\cdot e^{T_{33}^{\mathrm{T}}\left(C_{2 I}+S_{3}^{\mathrm{T}} C_{1 I} S_{3}\right) T_{33}\left(t-t_{0}\right)} X_{0}\right] \\
& +E\left[\left(\int_{t_{0}}^{t} e^{T_{33}^{\mathrm{T}}\left(C_{2 I}+S_{3}^{\mathrm{T}} C_{1 I} S_{3}\right) T_{33}(t-s)} T_{33}^{\mathrm{T}} Q d B(s)\right)^{\mathrm{T}}\right. \\
& \left.\cdot \int_{t_{0}}^{t} e^{T_{33}^{\mathrm{T}}\left(C_{2 I}+S_{3}^{\mathrm{T}} C_{1 I} S_{3}\right) T_{33}(t-s)} T_{33}^{\mathrm{T}} Q d B(s)\right] .
\end{aligned}
$$


Then, we analyze the right-side items of this inequality separately. For the first item, owing to the definition of vector norm and inequality (30) in Lemma 7, we obtain

$$
\begin{aligned}
& E\left[\left(e^{T_{33}^{\mathrm{T}}\left(C_{2 I}+S_{3}^{\mathrm{T}} C_{1 I} S_{3}\right) T_{33}\left(t-t_{0}\right)} X_{0}\right)^{\mathrm{T}}\right. \\
& \left.\cdot e^{T_{33}^{\mathrm{T}}\left(C_{2 I}+S_{3}^{\mathrm{T}} C_{1 I} S_{3}\right) T_{33}\left(t-t_{0}\right)} X_{0}\right] \\
& \quad=E\left|e^{T_{33}^{\mathrm{T}}\left(C_{2 I}+S_{3}^{\mathrm{T}} C_{1 I} S_{3}\right) T_{33}\left(t-t_{0}\right)} X_{0}\right|^{2} \leq \beta\left|X_{0}\right|^{2} e^{-\alpha\left(t-t_{0}\right)} .
\end{aligned}
$$

For the second and third items, by the features of Wiener process, we have

$$
\begin{aligned}
& E\left[\left(e^{T_{33}^{\mathrm{T}}\left(C_{2 I}+S_{3}^{\mathrm{T}} C_{1 I} S_{3}\right) T_{33}\left(t-t_{0}\right)} X_{0}\right)^{\mathrm{T}}\right. \\
& \left.\cdot \int_{t_{0}}^{t} e^{T_{33}^{\mathrm{T}}\left(C_{2 I}+S_{3}^{\mathrm{T}} C_{1 I} S_{3}\right) T_{33}(t-s)} T_{33}^{\mathrm{T}} Q d B(s)\right]=0, \\
& E\left[\left(\int_{t_{0}}^{t} e^{T_{33}^{\mathrm{T}}\left(C_{2 I}+S_{3}^{\mathrm{T}} C_{1 I} S_{3}\right) T_{33}(t-s)} T_{33}^{\mathrm{T}} Q d B(s)\right)^{\mathrm{T}}\right. \\
& \left.\cdot e^{T_{33}^{\mathrm{T}}\left(C_{2 I}+S_{3}^{\mathrm{T}} C_{1 I} S_{3}\right) T_{33}\left(t-t_{0}\right)} X_{0}\right]=0 .
\end{aligned}
$$

For the fourth item, using Ito isometry formula and Lemma 7, we have

$$
\begin{aligned}
& E\left[\left(\int_{t_{0}}^{t} e^{T_{33}^{\mathrm{T}}\left(C_{2 I}+S_{3}^{\mathrm{T}} C_{1 I} S_{3}\right) T_{33}(t-s)} T_{33}^{\mathrm{T}} Q d B(s)\right)^{\mathrm{T}}\right. \\
& \left.\cdot \int_{t_{0}}^{t} e^{T_{33}^{\mathrm{T}}\left(C_{2 I}+S_{3}^{\mathrm{T}} C_{1 I} S_{3}\right) T_{33}(t-s)} T_{33}^{\mathrm{T}} Q d B(s)\right] \\
& =E\left|\int_{t_{0}}^{t} e^{T_{33}^{\mathrm{T}}\left(C_{2 I}+S_{3}^{\mathrm{T}} C_{1 I} S_{3}\right) T_{33}(t-s)} T_{33}^{\mathrm{T}} Q d B(s)\right|^{2} \\
& =\int_{t_{0}}^{t} E\left|e^{T_{33}^{\mathrm{T}}\left(C_{2 I}+S_{3}^{\mathrm{T}} C_{1 I} S_{3}\right) T_{33}(t-s)} T_{33}^{\mathrm{T}} Q\right|^{2} d s \\
& \leq \int_{t_{0}}^{t} \beta\left|T_{33}^{\mathrm{T}} \mathrm{Q}\right|^{2} e^{-\alpha(t-s)} d s \\
& =\frac{\beta\left|T_{33}^{\mathrm{T}} Q\right|^{2}\left(1-e^{-\alpha\left(t-t_{0}\right)}\right)}{\alpha} .
\end{aligned}
$$

Overall, it is proposed that

$$
\begin{aligned}
(E|X(t)|)^{2} \leq & E\left[X^{\mathrm{T}}(t) X(t)\right] \\
\leq & \beta\left|X_{0}\right|^{2} e^{-\alpha\left(t-t_{0}\right)} \\
& +\frac{\beta\left|T_{33}^{\mathrm{T}} Q\right|^{2}\left(1-e^{-\alpha\left(t-t_{0}\right)}\right)}{\alpha} .
\end{aligned}
$$

Considering that $\alpha>0$ and $\beta>0$, take a limit on both sides and we have

$$
\lim _{t \rightarrow \infty}(E|X(t)|)^{2} \leq \frac{\beta\left|T_{33}^{\mathrm{T}} Q\right|^{2}}{\alpha} .
$$

Let $\gamma>\sqrt{\beta\left|T_{33}^{\mathrm{T}} Q\right|^{2} / \alpha}$. If $\gamma=\sqrt{\beta\left|T_{33}^{\mathrm{T}} \mathrm{Q}\right|^{2} / \alpha}+1$, then $\lim _{t \rightarrow \infty} E|X(t)|<\gamma$. By Definition 3, model (12) for power markets with interval parameters is proved to be mean interval stable.

In particular, let $Z=I$ and $h_{1}=h_{2}=1$; then, we have inferences below.

Corollary 9. For model (12) for power markets with interval parameters, if $\lambda_{\text {max }}\left(T_{33}^{T} C_{3} T_{33}\right)+\left(\left\|\widetilde{C}_{2}\right\|+\left\|\widetilde{C}_{1}\right\| \cdot\left\|S_{3}\right\|^{2}\right)\left\|T_{33}\right\|^{2}<0$, then the system is mean interval stable.

A concise criterion on the stability of the stochastic model for power markets with interval parameters is given in the corollary. It suggests that using this criterion can structure a stable interval matrix of the system and find out the value range of suppliers and consumers demand elasticity, which makes the system stable.

Remark 10. According to Theorem 8 and Corollary 9 above, we find the corollary strongly effective and practical. When $\widetilde{C}_{1}=\widetilde{C}_{2}=0$ in Corollary $9, C$ is a certain matrix and the consumers demand elasticity is certain. Then, the stability determine condition of model (12) can be simplified as $\lambda_{\text {max }}\left(T_{33}^{\mathrm{T}} C_{3} T_{33}\right)<0$; that is to say, all eigenvalues of $C_{3}$ are negative, which is consistent with Theorem 2 in [10] and theorem in [25]. If $Q=0$, then the model gets rid of random factors and becomes a deterministic model, which agrees with the theorem in [24]. So we can see that the mean interval stable Theorem 8 and Corollary 9 are a generalization of $[24,25]$.

\section{The Numerical Examples}

In this part, we begin to use Theorem 8 and Corollary 9 above to analyze the stochastic model for power markets with interval parameters. Since the linear interval stochastic model (19) is an equivalent transformation of model (12), we present the numerical examples of power market model (19) in order to analyze numbers and simulate numbers. These data are derived from Table 1 in [8], corresponding to a determinacy electricity market dynamic model proposed by Alvarado.

In the power market stochastic model (12), consider the set of differential/algebraic equations (DAE) corresponding to the case of three suppliers and two consumers. The demands elasticity of suppliers is $0.3,0.5$, and 0.2 , and response speeds of generation power output are $0.1,0.3$, and 0.2 ; the demands elasticity of consumers is -0.5 and -0.6 , and expansion speeds of consumer demands are 0.2 and 0.25 , respectively. The steady-state values of the power demand are 
7.68 and 8.05; when the disturbed values are 0.5 and 0.25 , and stochastic excitations are 0.03 and 0.06 , respectively:

$$
\begin{aligned}
& S_{1}=\left[\begin{array}{ccc}
1 & 1 & 1 \\
0.1 & -0.1 & 0 \\
0.2 & 0 & 0.3
\end{array}\right], \\
& S_{2}=\left[\begin{array}{cc}
-1 & -1 \\
0.1 & -0.1 \\
-0.1 & -0.1
\end{array}\right] .
\end{aligned}
$$
follows:

The corresponding data of model (19) are represented as

$$
\begin{aligned}
C_{1} & =\operatorname{diag}\{-0.3,-0.5,-0.2\}, \\
C_{2} & =\operatorname{diag}\{-0.5,-0.6\}, \\
S_{3} & =[0.25,-1.25 ;-0.75,-0.25 ;-0.5,0.5], \\
T_{33} & \approx[-1.435,0.550 ;-0.594,-1.326], \\
Q & =\left[\begin{array}{ll}
0.03 & 0.06
\end{array}\right]^{\mathrm{T}}, \\
P_{2}(t) & =\left[P_{d 1}(t), P_{d 2}(t)\right]^{\mathrm{T}} .
\end{aligned}
$$

We compute

$$
\begin{gathered}
\lambda_{\max }\left(T_{33}^{\mathrm{T}} C_{3} T_{33}\right)+\left(\left\|\widetilde{C}_{2}\right\|+\left\|\widetilde{C}_{1}\right\| \cdot\left\|S_{3}\right\|^{2}\right)\left\|T_{33}\right\|^{2} \\
=-2+2.412\left(\left\|\widetilde{C}_{2}\right\|+4\left\|\widetilde{C}_{1}\right\|\right)<0 .
\end{gathered}
$$

If $\left\|\widetilde{C}_{2}\right\|+4\left\|\widetilde{C}_{1}\right\|<0.8292$, then we have the conditions of Corollary 9 fulfilled. Let $\Delta C_{1}=\operatorname{diag}\{0.23,0.21,0.23\}$ and $\Delta C_{2}=\operatorname{diag}\{0.35,0.361\}$; then,

$$
\begin{aligned}
& \left\|\Delta C_{2}\right\|+4\left\|\Delta C_{1}\right\|=0.3419<0.8292, \\
& \lambda_{\max }\left(T_{33}^{\mathrm{T}} C_{3} T_{33}\right)+\left(\left\|\Delta C_{2}\right\|+\left\|\Delta C_{1}\right\| \cdot\left\|S_{3}\right\|^{2}\right)\left\|T_{33}\right\|^{2} \\
& \quad=-0.0113<0,
\end{aligned}
$$

which meets the conditions of Corollary 9, suggesting the range is valid. We obtain

$$
\begin{aligned}
& \underline{C}_{1}=\operatorname{diag}\{-0.53,-0.71,-0.43\}, \\
& \underline{C}_{2}=\operatorname{diag}\{-0.85,-0.961\}, \\
& \bar{C}_{1}=\operatorname{diag}\{-0.07,-0.29,0.03\}, \\
& \bar{C}_{2}=\operatorname{diag}\{-0.15,-0.239\} .
\end{aligned}
$$

We can also obtain the specific changing range of both sides of demand elasticity $0.07 \leq c_{g 1} \leq 0.53,0.29 \leq c_{g 2} \leq 0.71$, $-0.03 \leq c_{g 3} \leq 0.43,-0.85 \leq c_{d 1} \leq-0.15$, and $-0.961 \leq c_{d 2} \leq$ -0.239 .

Known from Theorem 8, system (19) is stable if the respective parameter is in the range above. Next, we begin the numerical stimulation to prove our theoretical analysis
TABLE 1: A three-supplier two-consumer case with increasing degrees of congestion.

\begin{tabular}{ccccccccc}
\hline & \multicolumn{3}{c}{ Suppliers } & \multicolumn{3}{c}{ Consumers } & \multicolumn{3}{c}{ Stable solutions } \\
$n_{S}$ & $\tau_{g}$ & $c_{g}$ & $b_{g}$ & $\tau_{d}$ & $c_{d}$ & $b_{d}$ & $P_{g}$ & $P_{d}$ \\
\hline \multirow{4}{*}{0} & 0.1 & 0.3 & 1 & 0.20 & -0.50 & 10 & 7.54 & 13.48 \\
& 0.3 & 0.5 & 2 & 0.25 & -0.60 & 8 & 2.52 & 7.90 \\
& 0.2 & 0.2 & 1 & & & & 11.31 & \\
\hline \multirow{4}{*}{1} & 0.1 & 0.3 & 1 & 0.20 & -0.50 & 10 & 0.40 & 8.53 \\
& 0.3 & 0.5 & 2 & 0.25 & -0.60 & 8 & 7.47 & 11.47 \\
& 0.2 & 0.2 & 1 & & & & 12.13 & \\
\hline \multirow{3}{*}{2} & 0.1 & 0.3 & 1 & 0.20 & -0.50 & 10 & 1.89 & 7.68 \\
& 0.3 & 0.5 & 2 & 0.25 & -0.60 & 8 & 11.52 & 8.05 \\
& 0.2 & 0.2 & 1 & & & & 2.31 & \\
\hline \multirow{3}{*}{3} & 0.1 & 0.3 & 1 & 0.20 & -0.50 & 10 & 2.30 & 7.56 \\
& 0.3 & 0.5 & 2 & 0.25 & -0.60 & 8 & 11.51 & 8.35 \\
& 0.2 & 0.2 & 1 & & & & 2.10 & \\
\hline
\end{tabular}

effective. Select several typical sets of data who have the greatest change of demand elasticity: the suppliers demand elasticity is $0.53,0.71$, and 0.43 and the consumers' is -0.15 and -0.239 . When $t_{0}=1 \mathrm{~s}$, set the electricity demand's disturbed value of consumer 1 and consumer 2 to be, respectively, 0.5 and 0.25 and the excitation of electricity demand to be 0.03 and 0.06 . Compare electricity demand of consumers with and without the stochastic excitation.

Based on statistics theory, if one solution process is regarded as a sample from population, the average value of many solution processes is the mean value of samples. Equations below are used to calculate sample's expectation and deviation percentage:

$$
\begin{aligned}
E_{P_{d}} & =\frac{1}{N} \sum_{k=1}^{N} P_{d}(k), \\
\varepsilon_{P_{d}} & =\frac{E_{P_{d}}-E_{P_{d 0}}}{E_{P_{d 0}}} \times 100 \%,
\end{aligned}
$$

where $P_{d}(k)$ represents the samples and $N$ is the total number of samples. $E_{P_{d 0}}$ are calculated by E-M numerical methods.

Adding stochastic excitations and disturbed values when $t_{0}=1 \mathrm{~s}$, we can calculate sample means of consumer 1 and consumer 2 electricity demand and the deviation between the electricity demands with and without random excitations. Results are presented in Tables 2 and 3.

It turns out that the sample's expected value of electricity demand gradually comes to a steady-state value and the error decreases to zero with the increase of the time. It suggests that the changing demand elasticity has no effects on the system's stability while demand elasticity of suppliers and consumers is in the given range; and small Gauss type random excitation causes only bounded stochastic fluctuation to the power system, instead of affecting its stability.

In order to directly measure the changing trend of consumer 1 and consumer 2 electricity demand, Tables 1 and 2, respectively, illustrate their steady-state value and the solution processes over 500 paths of sample's expected values, 
TABLE 2: Expected values and relative errors of solution process samples of consumer 1 in different time.

\begin{tabular}{lcc}
\hline$t(\mathrm{~s})$ & Expected value & Relative error $(\%)$ \\
\hline 2 & 7.883 & 1.986 \\
3 & 7.765 & 1.039 \\
4 & 7.715 & 0.443 \\
5 & 7.693 & 0.171 \\
6 & 7.684 & 0.058 \\
7 & 7.681 & 0.017 \\
8 & 7.681 & 0.013 \\
9 & 7.681 & 0.009 \\
10 & 7.680 & 0.005 \\
\hline
\end{tabular}

TABLE 3: Expected values and relative errors of solution process samples of consumer 2 in different time.

\begin{tabular}{lcc}
\hline$t(\mathrm{~s})$ & Expected value & Relative error $(\%)$ \\
\hline 2 & 8.181 & 1.430 \\
3 & 8.118 & 0.840 \\
4 & 8.087 & 0.456 \\
5 & 8.071 & 0.261 \\
6 & 8.059 & 0.114 \\
7 & 8.053 & 0.036 \\
8 & 8.054 & 0.044 \\
9 & 8.053 & 0.031 \\
10 & 8.053 & 0.034 \\
\hline
\end{tabular}

while $t_{0}=1 \mathrm{~s}$ and the random excitation term as well as disturbed value are added to the system; path 1 and path 2 are two of the 500 paths. We can figure out throughout the trend that random excitation terms and given demand elasticity do not play a role in the system's stability. The sample mean of system's solution processes is asymptotically stable, then the system is mean interval stable. then,

Conversely, let $\Delta \widehat{C}_{1}=\Delta C_{1}$ and $\Delta \widehat{C}_{2}=\operatorname{diag}\{0.8,-0.361\}$;

$$
\begin{aligned}
& \left\|\Delta C_{2}\right\|+4\left\|\Delta C_{1}\right\|=0.8516>0.8292, \\
& \lambda_{\max }\left(T_{33}^{\mathrm{T}} C_{3} T_{33}\right)+\left(\left\|\Delta C_{2}\right\|+\left\|\Delta C_{1}\right\| \cdot\left\|S_{3}\right\|^{2}\right)\left\|T_{33}\right\|^{2} \\
& \quad=2.9531>0,
\end{aligned}
$$

which does not satisfy the conditions of Theorem 8 and Corollary 9, suggesting the range is not valid. Take the consumers demand elasticity as 0.3 and -0.239 with other data unchanged; Figures 3 to 4 correspond to Figures 1 to 2, illustrating that the system is not mean stable, which indicates that the system may not be mean stable if Theorem 8 and Corollary 9 are not satisfied.

Remark 11. Applying the mean interval stable Theorem 8 and Corollary 9 in this article, demand elasticity $C_{1}$ and $C_{2}$ in [10, 20] can be generalized to intervals $\left[\underline{C}_{1}, \bar{C}_{1}\right]$ and $\left[\underline{C}_{2}, \bar{C}_{2}\right]$, that is to say, the demand elasticity varies in a certain range, and

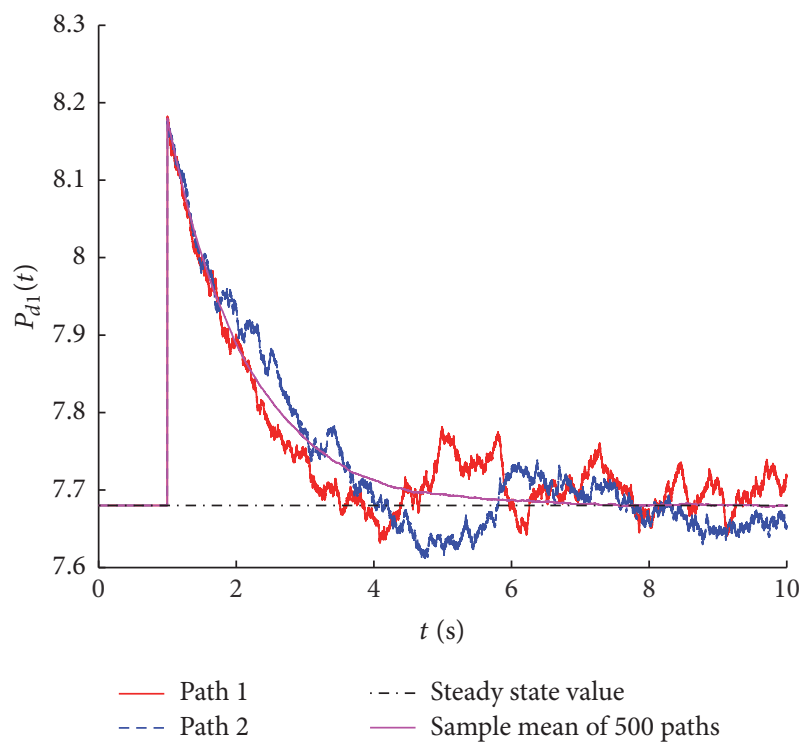

FIgURe 1: Average consumption demand of consumer 1 over 500 paths when we have $\Delta C_{1}=\operatorname{diag}\{0.23,0.21,0.23\}$ and $\Delta C_{2}=$ $\operatorname{diag}\{0.35,0.361\}$.

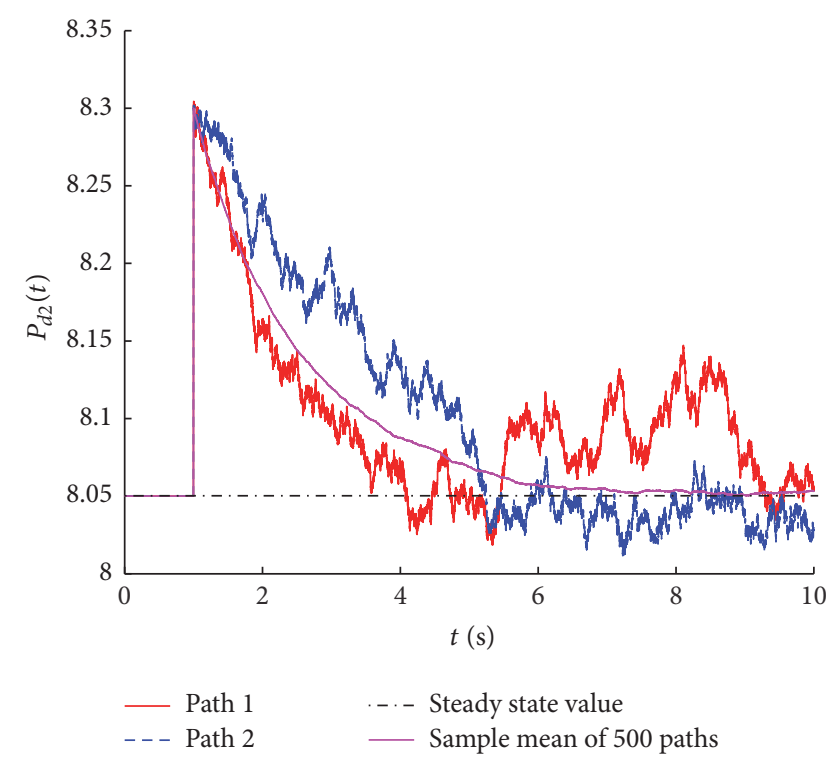

FIgURE 2: Average consumption demand of consumer 2 over 500 paths when we have $\Delta C_{1}=\operatorname{diag}\{0.23,0.21,0.23\}$ and $\Delta C_{2}=$ $\operatorname{diag}\{0.35,0.361\}$.

the system's mean interval stability remains. Comparing to [24], we discuss the stochastic features of electricity demand and objective factors affecting system stability, which makes the conclusion more practical.

\section{Conclusions}

(1) Based on the power market dynamic action model proposed by Alvarado, a stochastic model for power 


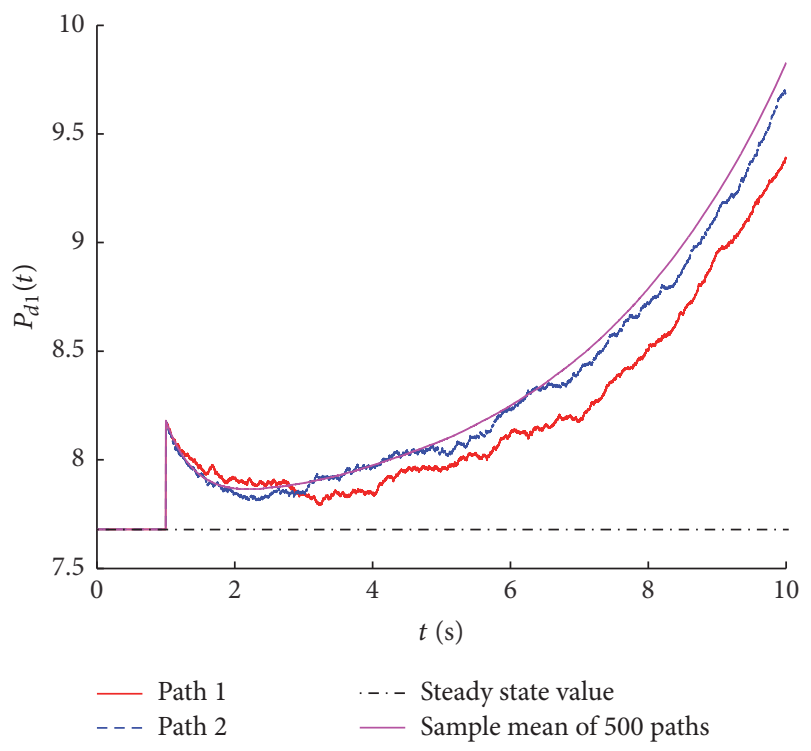

FIgURE 3: Average consumption demand of consumer 1 over 500 paths when $\Delta \widehat{C}_{1}=\Delta C_{1}$ and $\Delta \widehat{C}_{2}=\operatorname{diag}\{0.8,-0.361\}$.

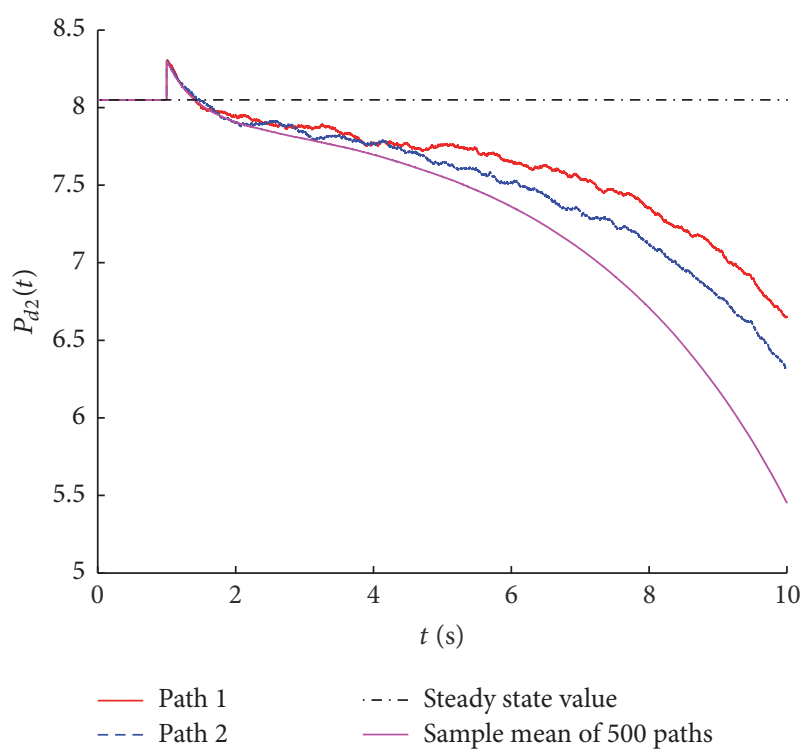

FIgURE 4: Average consumption demand of consumer 2 over 500 paths when $\Delta \widehat{C}_{1}=\Delta C_{1}$ and $\Delta \widehat{C}_{2}=\operatorname{diag}\{0.8,-0.361\}$.

markets with interval parameters is presented considering electricity demand's stochastic features caused by economic growth, industrial structure, and energy consumption pattern adjusting, as well as the interval features of consumers changing demand elasticity.

(2) Using the theory of economics, interval dynamic system, stochastic differential equations stability, and so on, proper Lyapunov functions are structured to analyze the system's stability; then, the stability criterion for this model is provided.
(3) The results of numerical examples are consistent with the stability analysis. The conditions are proved to be effective. The research method of this paper is expected to analyze the stability of nonlinear model for power market in future.

\section{Competing Interests}

The authors declare that they have no competing interests.

\section{Acknowledgments}

This work was supported by the Major Program Natural Science Foundation, China, 51190103.

\section{References}

[1] F. Lai and Q. Xia, "Electricity characteristics and electricity market," Automation of Electric Power Systems, vol. 29, no. 22, pp. 1-5, 2005.

[2] Y. Xue, "Interactions between power market stability and power system stability," Automation of Electric Power Systems, vol. 26, no. 21, pp. 1-33, 2003.

[3] C. Ruiz, A. J. Conejo, and R. García-Bertrand, "Some analytical results pertaining to Cournot models for short-term electricity markets," Electric Power Systems Research, vol. 78, no. 10, pp. 1672-1678, 2008.

[4] J.-F. Hu, C.-J. Li, H.-R. Zhao, and Z.-H. Lu, “The relationship between price elasticity of demand and generation market equilibrium analysis based on game theory," Proceedings of the CSEE, vol. 28, no. 1, pp. 89-94, 2008.

[5] E. Bompard, W. Lu, and R. Napoli, "Network constraint impacts on the competitive electricity markets under supply-side strategic bidding," IEEE Transactions on Power Systems, vol. 21, no. 1, pp. 160-170, 2006.

[6] X. Wang, M. Xie, and S. Zhang, "Analysis on equilibrium of electricity market under grid-integration of electric vehicles," Power System Technology, vol. 38, no. 11, pp. 2993-2998, 2014.

[7] B. Beavis and I. M. Dobbs, Optimization and Stability Theory for Economic Analysis, Cambridge University Press, Cambridge, UK, 1990.

[8] F. Alvarado, "The stability of power system markets," IEEE Transactions on Power Systems, vol. 14, no. 2, pp. 505-511, 1999.

[9] F. L. Alvarado, J. Meng, W. S. Mota, and C. L. DerMarco, "Dynamic coupling between power markets and power system," in Proceedings of the IEEE Power Engineering Society Summer Meeting, pp. 16-20, July 2000.

[10] Y. Zhihui, L. Youfei, T. Yun et al., "Analysis of power market stability," Proceedings of the CSEE, vol. 25, no. 2, pp. 1-5, 2005.

[11] L. Zhanhui, L. Gengyin, Z. Ming et al., "Decision conditions of electricity market practical stability," Mathematics in Practice and Theory, vol. 39, no. 4, pp. 54-61, 2009.

[12] Y.-H. Hou and F. F. Wu, "Stability of electricity market with cyclic load demand," Proceedings of the CSEE, vol. 26, no. 24, pp. 12-17, 2006.

[13] H. Yunhe, Research on the Power System Optimization Based on the Swarm Intelligence Algorithms and the Power Market Stability, Huazhong University of Science and Technology, 2005. 
[14] G. Bonanno, D. Valenti, and B. Spagnolo, "Mean escape time in a system with stochastic volatility," Physical Review E-Statistical, Nonlinear, and Soft Matter Physics, vol. 75, no. 1, Article ID 016106, 2007.

[15] G. Bonanno, D. Valenti, and B. Spagnolo, "Role of noise in a market model with stochastic volatility," European Physical Journal B, vol. 53, no. 3, pp. 405-409, 2006.

[16] B. Spagnolo and D. Valenti, "Volatility effects on the escape time in financial market models," International Journal of Bifurcation and Chaos, vol. 18, no. 9, pp. 2775-2786, 2008.

[17] G. Bonanno and B. Spagnolo, "Escape times in stock markets," Fluctuation and Noise Letters, vol. 5, no. 2, pp. L325-L330, 2005.

[18] D. Valenti, B. Spagnolo, and G. Bonanno, "Hitting time distributions in financial markets," Physica A. Statistical Mechanics and its Applications, vol. 382, no. 1, pp. 311-320, 2007.

[19] C. Rakpenthai, S. Uatrongjit, and S. Premrudeeprechacharn, "State estimation of power system considering network parameter uncertainty based on parametric interval linear systems," IEEE Transactions on Power Systems, vol. 27, no. 1, pp. 305-313, 2012.

[20] J. Zhang, P. Ju, Y. Yu, and F. Wu, "Responses and stability of power system under small Gauss type random excitation," Science China Technological Sciences, vol. 55, no. 7, pp. 18731880, 2012.

[21] Z. Lu, W. Zhao, D. Xie, and G. Li, "P-moment stability of power system under small Gauss type random excitation," Chaos, Solitons \& Fractals, vol. 81, pp. 30-37, 2015.

[22] Q. Zhu, "Asymptotic stability in the pth moment for stochastic differential equations with Lévy noise," Journal of Mathematical Analysis and Applications, vol. 416, no. 1, pp. 126-142, 2014.

[23] Q. Zhu, "Pth Moment exponential stability of impulsive stochastic functional differential equations with Markovian switching," Journal of the Franklin Institute, vol. 351, no. 7, pp. 3965-3986, 2014.

[24] W. Wang, Z. Lu, and Q. Zhu, "The interval stability of an electricity market model," Mathematical Problems in Engineering, vol. 2014, Article ID 547485, 8 pages, 2014.

[25] Z. Lu, W. Wang, G. Li, and D. Xie, "Electricity market stochastic dynamic model and its mean stability analysis," Mathematical Problems in Engineering, vol. 2014, Article ID 207474, 8 pages, 2014.

[26] X. Yusheng, L. Xing, X. Feng et al., "A review on impacts of wind power uncertainties on power systems," Proceedings of the CSEE, vol. 34, no. 29, pp. 5029-5040, 2014.

[27] Q. Zhu and J. Cao, "Mean-square exponential input-to-state stability of stochastic delayed neural networks," Neurocomputing, vol. 131, pp. 157-163, 2014.

[28] Q. Zhu and J. Cao, "Robust exponential stability of markovian jump impulsive stochastic Cohen-Grossberg neural networks with mixed time delays," IEEE Transactions on Neural Networks, vol. 21, no. 8, pp. 1314-1325, 2010.

[29] Q. Zhu and J. Cao, "Stability analysis of markovian jump stochastic BAM neural networks with impulse control and mixed time delays," IEEE Transactions on Neural Networks and Learning Systems, vol. 23, no. 3, pp. 467-479, 2012.

[30] M. Zhien and Z. Yicang, Qualitative and Stability for Ordinary Differential Equations, Science Press, Beijing, China, 2005.

[31] K. Benjelloun and E. K. Boukas, "Mean square stochastic stability of linear time-delay system with Markovian jumping parameters," IEEE Transactions on Automatic Control, vol. 43, no. 10, pp. 1456-1460, 1998.
[32] W. Songgui, W. Mixia, and J. Zhongzhen, Matrix Inequality, Science Press, Beijing, China, 2006.

[33] X. Mao, Stochastic Differential Equations and Applications, Horwood, Chichester, UK, 2007.

[34] Z. Binggen and Z. Yuzhi, Stochastic Differential Equations in Science and Engineering, Beijing Ocean Press, 1998. 


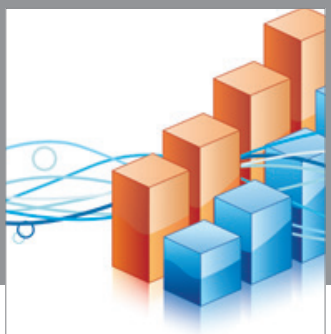

Advances in

Operations Research

vatem alat4

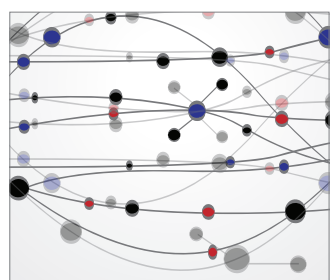

\section{The Scientific} World Journal
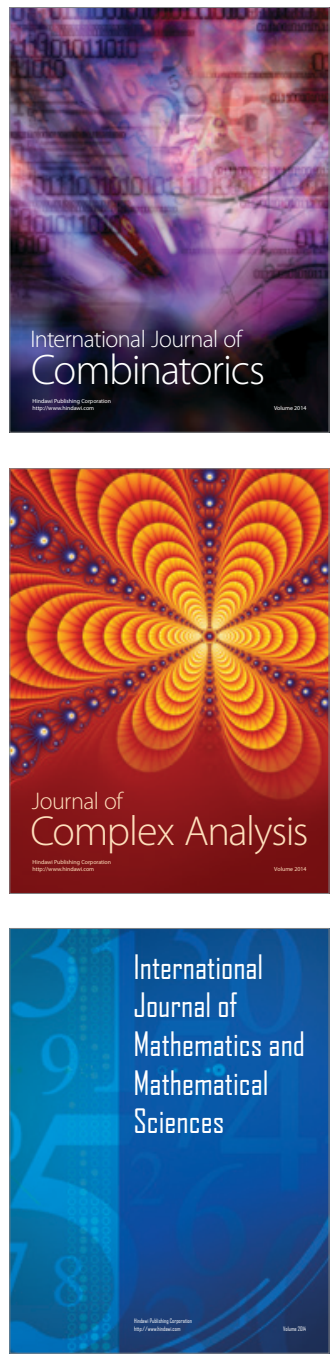
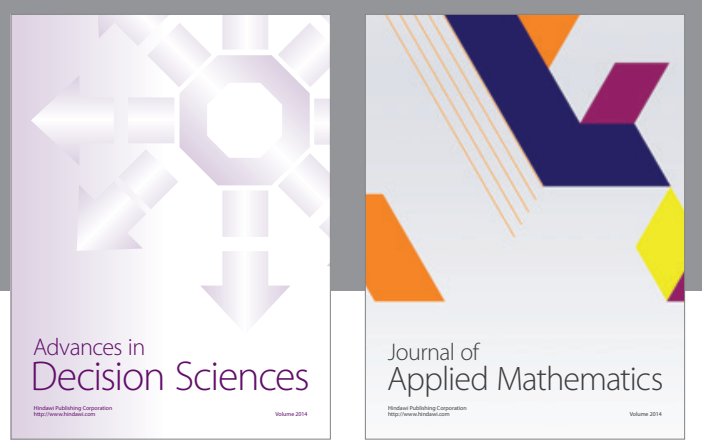

Algebra

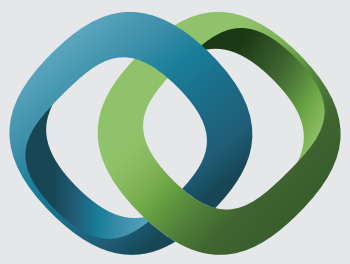

\section{Hindawi}

Submit your manuscripts at

http://www.hindawi.com
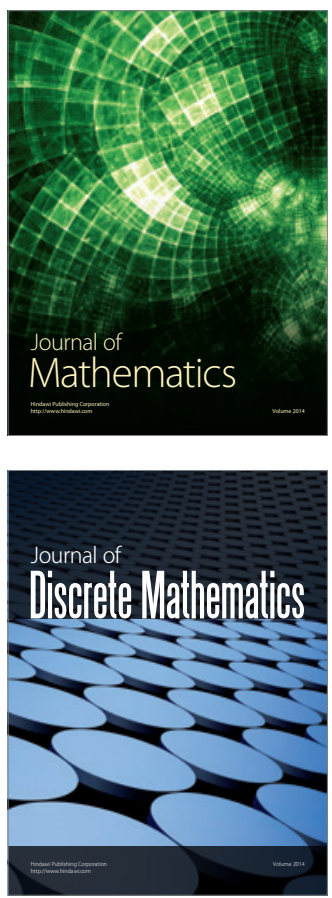

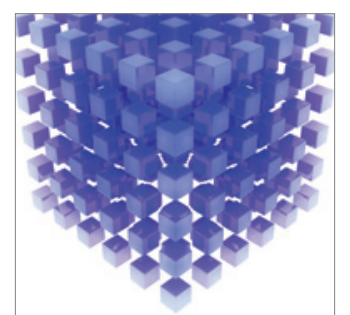

Mathematical Problems in Engineering
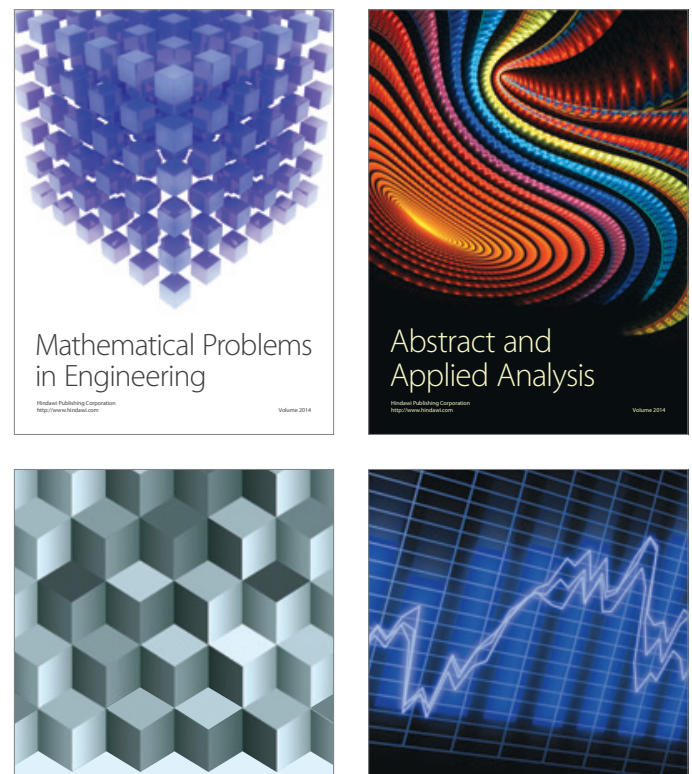

Journal of

Function Spaces

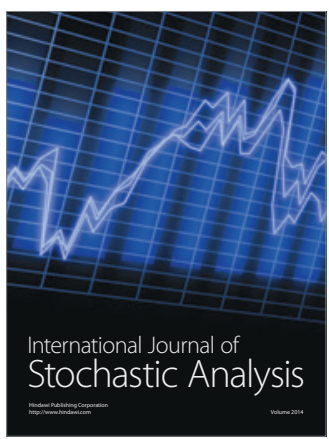

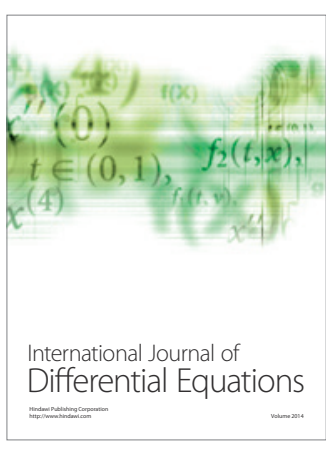
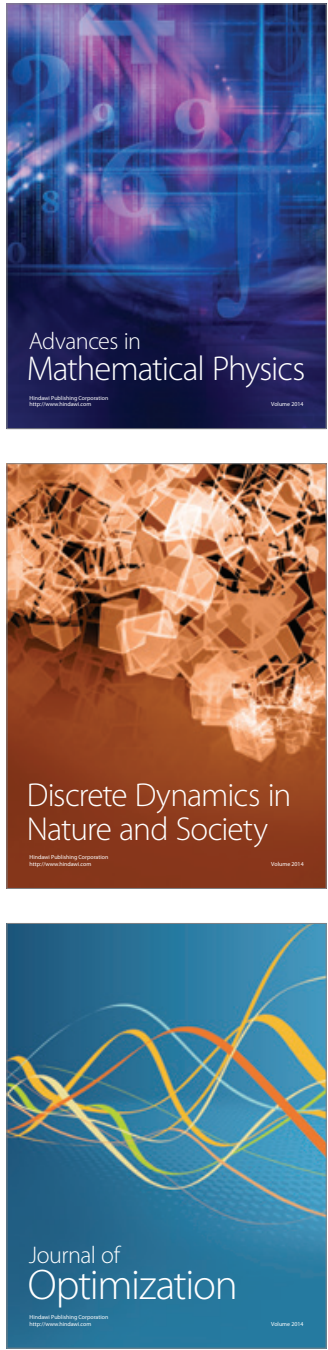